\title{
Deficiency of the clock gene Bmal1 affects neural progenitor cell migration
}

\author{
Amira A. H. Ali ${ }^{1} \cdot$ Beryl Schwarz-Herzke ${ }^{1}$ (1) Shakila Mir $^{1} \cdot$ Benita Sahlender $^{1} \cdot$ Marion Victor $^{1} \cdot$ Boris Görg $^{2}$. \\ Martin Schmuck ${ }^{3} \cdot$ Katharina Dach $^{3} \cdot$ Ellen Fritsche $^{3} \cdot$ Andreas Kremer $^{4} \cdot$ Charlotte von Gall $^{1}$
}

Received: 17 August 2017 / Accepted: 8 October 2018 / Published online: 19 October 2018

(c) The Author(s) 2018

\begin{abstract}
We demonstrate the impact of a disrupted molecular clock in Bmal1-deficient (Bmal1 $\left.{ }^{-/}\right)$mice on migration of neural progenitor cells (NPCs). Proliferation of NPCs in rostral migratory stream (RMS) was reduced in Bmal1 ${ }^{-1-}$ mice, consistent with our earlier studies on adult neurogenesis in hippocampus. However, a significantly higher number of NPCs from Bmal1 ${ }^{-/-}$mice reached the olfactory bulb as compared to wild-type littermates (Bmal1 ${ }^{+/+}$mice), indicating a higher migration velocity in $\mathrm{Bmal1}^{-/-}$mice. In isolated NPCs from Bmal1 ${ }^{-/-}$mice, not only migration velocity and expression pattern of genes involved in detoxification of reactive oxygen species were affected, but also RNA oxidation of catalase was increased and catalase protein levels were decreased. Bmal1 ${ }^{+/+}$migration phenotype could be restored by treatment with catalase, while treatment of NPCs from Bmal1 ${ }^{+/+}$mice with hydrogen peroxide mimicked Bmal1 ${ }^{-/-}$migration phenotype. Thus, we conclude that Bmal1 deficiency affects NPC migration as a consequence of dysregulated detoxification of reactive oxygen species.
\end{abstract}

Keywords Circadian $\cdot$ Clock genes $\cdot$ Bmal1 $\cdot$ Rostral migratory stream $\cdot$ Subventricular zone $\cdot$ Catalase $\cdot$ Hydrogen peroxide $\cdot$ Filopodia $\cdot$ Cytoskeleton $\cdot$ p-Cofilin $\cdot$ RNA oxidation

Amira A. H. Ali and Beryl Schwarz-Herzke contributed equally to this work.

Electronic supplementary material The online version of this article (https://doi.org/10.1007/s00429-018-1775-1) contains supplementary material, which is available to authorized users.

Charlotte von Gall

charlotte.vongall@med.uni-duesseldorf.de

1 Institute of Anatomy II, Medical Faculty, Heinrich Heine University, Moorenstrasse 5, 40225 Düsseldorf, Germany

2 Clinic for Gastroenterology, Hepatology and Infectiology, Medical Faculty, Heinrich Heine University, Moorenstrasse 5, 40225 Düsseldorf, Germany

3 Leibniz Research Institute for Environmental Medicine, Modern Risk Assessment and Sphere Biology Group, Auf'm Hennekamp 50, 40225 Düsseldorf, Germany

4 Department of Bioinformatics, Erasmus University Medical Center Rotterdam, 3015CN Rotterdam, The Netherlands

\section{Introduction}

Neurogenesis plays an important role in neuronal plasticity even in the adult brain. The subventricular zone (SVZ) of the lateral ventricles represents the most extensive neurogenic niches within the adult brain (Lois and Alvarez-Buylla 1994; Lim and Alvarez-Buylla 2016). It gives rise to neural progenitor cells (NPCs) which generate primarily committed neural progenitor that migrate tangentially along the rostral extension of the SVZ toward the olfactory bulb, forming the rostral migratory stream (RMS) (Lois and Alvarez-Buylla 1994; Doetsch and Alvarez-Buylla 1996; Jankovski and Sotelo 1996; Gritti et al. 2002; Lois et al. 1996). Within the RMS, NPCs form chains and continue to proliferate while migrating (Gritti et al. 2002; Wichterle et al. 1997). In mice, this considerable distance from the SVZ to the olfactory bulb of up to $5 \mathrm{~mm}$ is traversed by NPCs within 4-6 days (Lois and Alvarez-Buylla 1994). The migrating chains of NPCs in the RMS are surrounded by astrocytes that form glial tubes directing the migrating NPCs towards the olfactory bulb (Doetsch and Alvarez-Buylla 1996; Jankovski and Sotelo 1996; Lois et al. 1996). In the white matter of the olfactory bulb, the NPCs detach from the chains and 
change their direction and migrate radially to the cortex of the olfactory bulb. Finally, they differentiate into interneurons within the granule cell layer and the glomerular layer and integrate into preexisting neuronal networks (Whitman and Greer 2007; Carleton et al. 2003; Panzanelli et al. 2009). These adult-born interneurons play an important role in odor information processing and display a high degree of synaptic plasticity (Livneh et al. 2014). Efficient migration of NPCs within the RMS is a multifactorial process including intrinsic NPC properties as well as dynamic interactions between NPCs and glial tube astrocytes (Kaneko et al. 2010) and chemoattraction (Goldman and Luskin 1998). The circadian system provides an internal time keeping system to coordinate physiology and behavior within the $24 \mathrm{~h}$ solar day (Korf and von Gall 2012). The circadian clockwork is composed of two interlocked transcription/translation feedback loops of clock genes generating circadian rhythms in gene expression. The transcription factors brain and muscle Arnt-like protein1 (BMAL1) and circadian locomotor output cycles (CLOCK) heterodimerize, bind to E-box within gene promoters and enhance the transcription of genes encoding for clock genes such as Period (Per) and Cryptochrome (Cry) as well as of clock-controlled genes. PER and CRY proteins translocate into the nucleus, heterodimerize and inhibit CLOCK:BMAL1-mediated transcription and consequently their own expression. In addition, CLOCK:BMAL1 complex activates the transcription of nuclear receptors, REV-ERBa and RORa which regulate Bmall transcription (Ko and Takahashi 2006; Reppert and Weaver 2002). This molecular clockwork controls rhythmic gene expression and thus rhythmic cellular and organ function. BMAL1 is an essential component in the molecular clockwork as targeted deletion of the core clock gene Bmall leads to a loss of circadian rhythms in physiology and behavior. Moreover, Bmal1 is crucial for cellular redox homeostasis as Bmal1-deficient $\left(\mathrm{Bmal1}^{-/-}\right)$mice have increased levels of cellular oxidative stress resulting in reduced life span and premature aging (Kondratov et al. 2006). Bmall deficiency also affects cerebral redox homeostasis and is associated with cardinal symptoms of neurodegeneration (Musiek et al. 2013) as well as impaired learning and memory formation (Kondratova et al. 2010). Importantly, Bmall deficiency affects proliferation and differentiation of neuronal progenitor cells in the subgranular zone of the hippocampus (Malik et al. 2015) (Ali et al. 2015; Bouchard-Cannon et al. 2013). However, little is known about the effects of disrupted molecular clockwork on NPC migration. Therefore, we analyzed the impact of Bmall deficiency on NPC migration on both the systemic and the cellular level.

\section{Methods}

\section{Ethics}

All animal experiments were approved by the local government, North Rhine-Westphalia State Agency for Nature, Environment and Consumer Protection, Germany (application numbers: 84-02.04.2012.A102, 84-02.04.2014.A314) and in agreement with the ARRIVE international guidelines on the ethical use of animals (Kilkenny et al. 2012). For ethical and economical reasons, sample sizes were kept to a minimum (Festing and Altman 2002).

\section{Experimental animals}

Heterozygous mice with a targeted deletion of Bmal1 $\left(\mathrm{Bmal1}^{+-}\right)$on a C57BL/6 background, kindly provided by Christopher Bradfield, were kept for breeding at the local animal facility of University of Düsseldorf to obtain $\mathrm{Bmal1}^{-/-}$and Bmal1 ${ }^{+/+}$littermates. PCR was used to confirm the genotype (Bunger et al. 2000). Mice were housed in standard single cages, with controlled $12 \mathrm{~h}$ light/12 h darkness, lights on at 6:00 am and constant temperature conditions. Mice had free access to food and water. And, the mice were killed between 8:00 and 10:00 am.

\section{In vivo BrdU assay and tissue preparation for immunohistochemistry and immunofluorescence}

$12 \pm 2$ weeks male mice ( $n=8$ per genotype) were injected i.p. with BrdU (Roche, Switzerland) at a dose of $100 \mathrm{mg} /$ $\mathrm{kg}$ body weight, twice daily at the beginning and at the end of the light phase, on three consecutive days. One group of mice ( $n=4$ mice per genotype) was sacrificed 4 days after the first BrdU administration. The second group of mice ( $n=4$ mice per genotype) was sacrificed 31 days after the first BrdU administration. Animals were anaesthetized using Ketamine/Xylazine (100 mg/10 mg, respectively, / kg body weight), then perfused transcardially with $0.9 \% \mathrm{NaCl}$ followed by $4 \%$ paraformaldehyde using Ministar Peristaltic Pump (World Precision Instruments, USA). Brains were removed from the skull, post fixed in $4 \%$ paraformaldehyde for $24 \mathrm{~h}$, and cryoprotected in $20 \%$ sucrose for $24 \mathrm{~h}$. Brain hemispheres were sectioned on a cryostat (Leica CM, Germany) into $20-\mu \mathrm{m}$-thick sagittal sections.

\section{Immunohistochemistry and immunofluorescence}

Slides were washed with phosphate buffered saline (PBS) with $0.2 \%$ Triton- $\mathrm{X} 100$, incubated in $0.6 \% \mathrm{H}_{2} \mathrm{O}_{2}$ for $30 \mathrm{~min}$ 
at room temperature (RT), and then rinsed with PBS. For anti-BrdU staining, DNA was denatured by incubation with $2 \mathrm{~N} \mathrm{HCl}$ for $30 \mathrm{~min}$ at $37^{\circ} \mathrm{C}$, followed by $0.1 \mathrm{M}$ boric acid for $10 \mathrm{~min}$ at RT. Sections were blocked for $1 \mathrm{~h}$ with $10 \%$ normal goat serum, then incubated overnight at $4{ }^{\circ} \mathrm{C}$ with either one or a combination of two of the following primary antibodies against BrdU (1:800, AbD Serotec, UK) 8-hydroxy2'-deoxyguanosine (8-OH(d)G) (1:250, QED Bioscience, CA, USA), Doublecortin (DCX) (1:1000, Abchem, UK), and glial fibrilary acid protein (GFAP) (1:2000, DAKO, Denmark). For immunohistochemistry, slides were incubated with biotinylated secondary antibody for $3 \mathrm{~h}$ at RT, rinsed, then incubated with VECTASTAIN ${ }^{\circledR}$ Elite $^{\circledR}$ ABC solution (Vector Laboratories, CA, USA) for $1 \mathrm{~h}$ at RT followed by incubation with $0.05 \% 3,3^{\prime}$-Diaminobenzidine tetrahydrochloride hydrate (Sigma-Aldrich, MO, USA) for 5 min. Sections stained against BrdU were counterstained using cresyl violet. Slides were coverslipped using Depex (SERVA Electrophoresis, Germany). For immunofluorescence, slides were incubated with Alexa Fluor 488 goat anti rat $\operatorname{IgG}(1: 500$, Thermo Scientific, CA, USA) and Alexa Fluor 568 goat anti rabbit IgG (1:500, Thermo Scientific, CA, USA) for $1 \mathrm{~h}$ at RT. Slides were coverslipped using Vectashield Hard Set anti-fade reagent (Vector Laboratories, CA, USA) and kept in darkness at $4{ }^{\circ} \mathrm{C}$.

\section{Image acquisition and analysis of immunohistochemistry}

Images were acquired using BZ-9000E microscope (Keyence, Japan). All samples of an experiment were processed in one session in which microscope and camera settings were kept constant. All analyses were performed by an observer blind to the experimental condition/genotype. DAB-labeled BrdU-immunopositive (+) cells were counted in delineated areas in the SVZ as well as both the proximal and the distal limb of the RMS and in defined layers of the olfactory bulb (Supplementary Fig. 1) using 40x objective in bright field mode. Immunofluorescence was analyzed using respective filters. For analysis of BrdU/DCX co-labeling, 20 randomly selected $\mathrm{BrdU}^{+}$cells in olfactory bulb were examined. Colabeling was confirmed by $3 \mathrm{D}$ reconstruction of $\mathrm{Z}$ stack series using BZ Analyser software (Keyence, Japan). The width of RMS, determined by the area stained for DCX, was measured in at least seven different rostrocaudal levels in equivalent sections in each animal. Dispersion of $\mathrm{DCX}+$ cells from RMS into the neighboring structure was determined as previously described (Courtes et al. 2011). GFAP immunoreactivity of the glial tube surrounding the RMS, as well as 8-OH(d)G immunoreactivity in RMS and olfactory bulb were quantitatively analyzed using Image J software (http://rsbweb.nih.gov/ij). The threshold of immunoreaction was determined above background in cell body-free neuropil and kept constant for all measurements. The percentage of immunoreactive area relative to the total area was calculated for each section.

\section{Tissue preparation for gene expression analysis}

For gene expression analyses ex vivo, mice $(n=9-7$ per genotype) were killed by isoflurane and the olfactory bulb was dissected. Total RNA was isolated using RNeasy Lipid Tissue Mini Kit (Qiagen, Germany) according to the manufacturer's protocol.

\section{Neurosphere culture}

Bmal1 $1^{-/-}$mice and their wild-type littermates $\left(\mathrm{Bmal1} 1^{+/+}\right.$ mice) at age P0 to $\mathrm{P} 3$ were decapitated and brains were removed. NPCs were isolated after protocols previously described (Baumann et al. 2014; Fritsche et al. 2011). Briefly, the meninges, the brain stem and the cerebellum were removed. The forebrain was dissected and cut into small pieces $(100-150 \mu \mathrm{m})$ in ice-cold HBSS and incubated with papain $(27 \mathrm{U} / \mathrm{ml}$ in HBSS; Worthington PDS Kit) for $10 \mathrm{~min}$ at $37^{\circ} \mathrm{C}$. The enzyme was stopped using $1 \%$ ovomucoid solution $\left(1 \mathrm{mg} / \mathrm{ml}\right.$ in HBSS including $\mathrm{Ca}^{2+}$ and $\mathrm{Mg}^{2+}$ (Sigma-Aldrich, MO, USA) 1\% DNAse I (Roche Diagnostics, Switzerland), $0.5 \%$ BSA, $1 \%$ ovomucoid stock solution, DMEM. A single cell suspension was received using a sterile sieve ( $70 \mu \mathrm{m}$, Grainer). Cell debris were removed by centrifugation $(80 \times g)$ at $4{ }^{\circ} \mathrm{C}$ for $5 \mathrm{~min}$. Cells were seeded into $10 \mathrm{~cm}$ tissue culture plates and cultured in proliferation medium (DMEM/F12, B27 supplement, $20 \mathrm{ng} / \mathrm{ml} \mathrm{EGF,}$ $20 \mathrm{ng} / \mathrm{ml}$ bFGF, $1 \%$ PenStrep, $10 \mathrm{mM}$ HEPES) in a humidified incubator at $5 \% \mathrm{CO}_{2}$ for up to 10 days. Neurospheres at a size of $150 \mu \mathrm{m}$ in diameter were collected and centrifuged at $80 \times g$ for $10 \mathrm{~min}$ at $4{ }^{\circ} \mathrm{C}$. Supernatant was removed and neurospheres were incubated with $1 \mathrm{ml}$ Accutase for $5 \mathrm{~min}$ at $37^{\circ} \mathrm{C}$ and cultured in a humidified incubator at $5 \% \mathrm{CO}_{2}$. After four passages, neurospheres reached a diameter of 100-150 $\mu \mathrm{m}$, single neurospheres were collected and seeded on poly-d-lysine $\left(10 \mu \mathrm{g} / \mathrm{cm}^{2}\right)$-coated culture plates. For migration assays, neurospheres were cultured in migration medium (DMEM, 1\% PenStrep, $10 \mathrm{mM}$ HEPES and $1 \mathrm{x}$ B27 without vitamin A) with or without catalase $(500 \mathrm{U} / \mathrm{ml})$ (Valdameri et al. 2011), $\mathrm{H}_{2} \mathrm{O}_{2}(80 \mu \mathrm{M})$ (Perez Estrada et al. 2014) or $N$-acetylcysteine in various concentrations. Cell migration was continuously recorded for $24 \mathrm{~h}$ after seeding in cell culture micro-dishes (IBIDI, Germany) using life-cell imaging phase-contrast light microscopy (Axiovert, Zeiss, AxioVision-Software, Zeiss). Data were analyzed in $3 \mathrm{~h}$ intervals from 16 neurospheres per individual mouse. The average migration distance was calculated as the distance between the perimeter of the neurosphere and the perimeter of the leading front of the radially migrating cells (Baumann 
et al. 2015). The average migration velocity in $\mu \mathrm{m} / \mathrm{h}$ was calculated based on the migration distance. Migrating cells were identified as neural progenitors by immunocytochemistry for PSA-NCAM (Hack et al. 2002; Hu 2000; Chazal et al. 2000) and DCX (Supplementary Fig. 2). The absence of glia cells was confirmed by GFAP immunoreaction (Supplementary Fig. 2c). Analyses on NPC number (in 16 neurospheres per individual mouse) as well as on filopodia number and length per cell ( 7 per neurosphere) were performed $24 \mathrm{~h}$ after seeding the neurospheres in migration medium using Image J. Means for neurospheres from individual mice were calculated and data were expressed as mean \pm SEM of the number of individual mice per group $(n)$.

\section{Cytochemistry and immunocytochemistry}

$24 \mathrm{~h}$ after seeding, cells on culture plates were fixed with 4\% PFA for $1 \mathrm{~h}$ and rinsed with PBS. For high-affinity F-actin cytochemistry, the cells were incubated with Alexa Fluor 594-conjugated phalloidin (1:30, Thermo Scientific, CA, USA). For immunocytochemistry the cells were incubated with $10 \%$ normal goat serum in PBS-T $0.2 \%$ at RT for $1 \mathrm{~h}$, followed by an incubation with the primary antibodies against PSA-NCAM (1:200, Cell Signalling Technologies, Danvers, MA, USA), GFAP (1:500, DAKO; Denmark), DCX (1:1000, Abchem, UK), or 8-OH(d)G (1:250, QED Bioscience, CA, USA) for $12 \mathrm{~h}$ at RT. Additionally, a fraction of cells on culture plates were treated with $10 \mu \mathrm{g} / \mu \mathrm{l}$ DNase I (Qiagen, Germany), or $5 \mu \mathrm{g} / \mu \mathrm{l}$ RNase (Qiagen, Germany), before incubation with $8-\mathrm{OH}(\mathrm{d}) \mathrm{G}$ antibody. Culture plates were rinsed in PBS-T $0.2 \%$, followed by incubation with Alexa Fluor 488 or Alexa Fluor 647 conjugated secondary antibody against rabbit IgG (1:500, Molecular Probes, USA) for $1 \mathrm{~h}$ at RT. Cell nuclei were counterstained with NucBlue (Thermo Scientific, CA, USA). Culture plates were coverslipped using Vectashield Hard Set anti-fade reagent (Vector Laboratories, CA, USA) and stored in darkness at $4{ }^{\circ} \mathrm{C}$. The integrated density of 8-OH(d)G-Ir in NPCs above cell-free background was analyzed using Image $\mathbf{J}$ software.

\section{Immunoblot}

$24 \mathrm{~h}$ after seeding, NPCs (from 16 neurospheres per mouse) were lysated in M-Per buffer (Thermo Scientific, Germany) and sonicated on ice. Protein concentration was determined using BCA kit (Thermo Scientific, CA, USA). PAGE and Western blotting was performed using XCell Sure Lock Blot module (Thermo Scientific, CA, USA) following manufacturer's instructions. The membranes were washed in TBST and incubated with blocking solution (TBST containing 5\% milk powder, fat free, Sucofin, Germany) for $1 \mathrm{~h}$ at room temperature. Membranes were incubated with anti $\beta$-actin (1:1000, Cytoskeleton, CO, USA) and with anti-catalase
(1:2500, Santa Cruz, clone H-9: sc271803, Germany), anti phospho-cofilin (1:1000, Cell Signalling Technologies, MA, USA), or anti-SOD2 (1:1000, Abcam, UK) in 3\% BSA in TBST for $12 \mathrm{~h}$ at $4{ }^{\circ} \mathrm{C}$. After washing, membranes were incubated with secondary HRP-conjugated antibody for $1 \mathrm{~h}$ at RT. After washing, immunoreactive bands were visualized using Immobilon Western Chemiluminescent HRP substrate (Millipore, Germany) on the Molecular Imager ${ }^{\circledR}$ ChemiDoc ${ }^{\mathrm{TM}}$ XRS (BioRad, CAa, USA). Immunoreactive bands were normalized against $\beta$-actin using densitometric

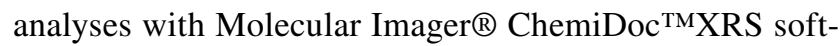
ware (BioRad, CA, USA). Catalase and SOD2 (+ $\beta$-actin) immunoblot were performed three times with NPCs from different mice ( $n=5$ mice per genotype). $\mathrm{p}$-Cofilin $(+\beta$-actin) immunoblot was performed once with NPCs from different mice ( $n=3$ mice per genotype).

\section{ROS imaging}

$24 \mathrm{~h}$ after seeding, oxidative stress in NPCs was detected using the ROS-sensitive dye CellROX® (Thermo Scientific, CA, USA) kit. NPCs were incubated with CellROX® reagent $(5 \mu \mathrm{M})$ for $30 \mathrm{~min}$ at $37^{\circ} \mathrm{C}$. As a positive control, NPCs were incubated with $1 \mathrm{mM}$ tert-butylhydroperoxid (TBHP) for $60 \mathrm{~min}$ at $37{ }^{\circ} \mathrm{C}$ prior CellROX® assay. Medium was removed, and NPCs were fixed in $4 \%$ paraformaldehyde for $15 \mathrm{~min}$ at $37^{\circ} \mathrm{C}$. The number of fluorescent cells above cell free background was counted using Image J.

\section{Immunoprecipitation of oxidized RNA}

Immunoprecipitation of oxidized RNA was performed as previously described (Shan et al. 2003; Gorg et al. 2008). Briefly, $24 \mathrm{~h}$ after seeding, NSCs were lysated in buffer containing $10 \mathrm{mM}$ Tris, $\mathrm{pH} 8,10 \mathrm{mM} \mathrm{NaCl} 2,1 \%$ Triton $\mathrm{X}$ 100 (Merck, Germany), $1.33 \mathrm{mg} / \mathrm{ml}$ Proteinase K (SigmaAldrich, MO, USA), $400 \mathrm{U} / \mathrm{ml}$ DNase I and $1 \mathrm{U} / \mathrm{ml}$ RNase Inhibitor (Qiagen, Germany) for $60 \mathrm{~min}$ at $37^{\circ} \mathrm{C}$. After centrifugation, the supernatant was collected and frozen at $-20{ }^{\circ} \mathrm{C} .8-\mathrm{OH}(\mathrm{d}) \mathrm{G}$ antibody (1:200, clone $15 \mathrm{~A} 3$, Acris, AM03160PU-N, Germany) which was crosslinked to $G$ sepahrose beads (Abcam, UK) using DMP (dimethyl pimelimidate, Abcam, UK) according to respective manufacturers protocols. The immunobeads were incubated with cell lysates for $2 \mathrm{~h}$ at $4{ }^{\circ} \mathrm{C}$. Immunopurified RNA was obtained by centrifugation for $30 \mathrm{~s}$ at $14,900 \mathrm{~g}$, extraction with phe$\mathrm{nol} /$ chloroform and precipitation with $100 \%$ isopropanol.

\section{Gene expression analyses}

cDNA of total RNA or immunoprecipitated oxidized RNA was prepared using QuantiTect Reverse transcription kit (Qiagen, Germany). The following PCR program was used 
for amplification: $15 \mathrm{~min}$ at $42{ }^{\circ} \mathrm{C}, 1 \mathrm{~min}$ at $95{ }^{\circ} \mathrm{C}$ then at $4{ }^{\circ} \mathrm{C}$. For PCR, Applied Biosystems StepOne ${ }^{\mathrm{TM}}$ Real-Time PCR Systems was used. Based on SYBR green reagents (KAPA SYBR FAST qPCR Kit master mix ABI Prism (KAPA Biosystems, South Africa) and the following primer sequences were used:

Aldh2 (F: TGCTACGATGTGTTTGGGGC, R: TTCACT TCTGTGTACGCCTGC), Nqol (F: CATTGCAGTGGT TTGGGGTG, R: TCTGGAAAGGACCGTTGTCG), $H g f$ (F: TGATCCCCCATGAACACAGC, R: CCCCTCGAG GATTTCGACAG), Prdm16 (F: GCCCCATGATGGACA AGACA, R: TCCCAGGATGAGGTCTGGAG), Sod2 (F: TCCGTCCGTCGGCTTCTCGT, R: TCACCGCTTGCC TTCTGCTCG), Ppara (F: TGAGGAAGCCGTTCTGTG AC; R: GTTTAGAAGGCCAGGCCGAT), Cat (F: GCC AATGGCAATTACCCGTC, R: GAGGCCAAACCTTGG TCAGA), 18srRNA (F: TACCGCCCCTCGTAGACAC, R: GCTCTGACCTCGCCACC), actin ß (Actb) (F: CCTTCC AGCAGATGTGGATCA, R: CTAGAAGCACTTGCGGTG CA), Gapdh (F: TGC CAA GGC TGT GGG CAA GG, R: CCA GGC GGC ACG TCA GAT CC). Actb and Gaphd were used as housekeeping genes. The average of the $\mathrm{Ct}$ values of both housekeeping genes was used to calculate the relative expression levels for the respective genes of interest (Vandesompele et al. 2002).

\section{Statistical analysis}

Statistics were calculated using Graph Pad Prism 6 software. Values are expressed as mean \pm SEM. Differences between two genotypes or between two treatments were analyzed by Mann-Whitney $U$ Test. Values were considered significantly different with $P<0.05$.

\section{Data availability}

The datasets generated during and/or analyzed during the current study are available from the corresponding author on reasonable request.

\section{Results}

\section{Bmal1 deficiency affects NPC proliferation in the SVZ and RMS}

To assess proliferation in the SVZ and RMS, the number of bromodeoxyuridine positive $\left(\mathrm{BrdU}^{+}\right)$cells was analyzed 4 days after the first BrdU injection. The number of $\mathrm{BrdU}^{+}$cells in the SVZ (Fig. 1a) as well as in the proximal (Fig. 1b) and in the distal RMS (Fig. 1c) was reduced in $\mathrm{Bmal1} 1^{-/-}$mice as compared to $\mathrm{Bmal1}{ }^{+/+}$mice. The
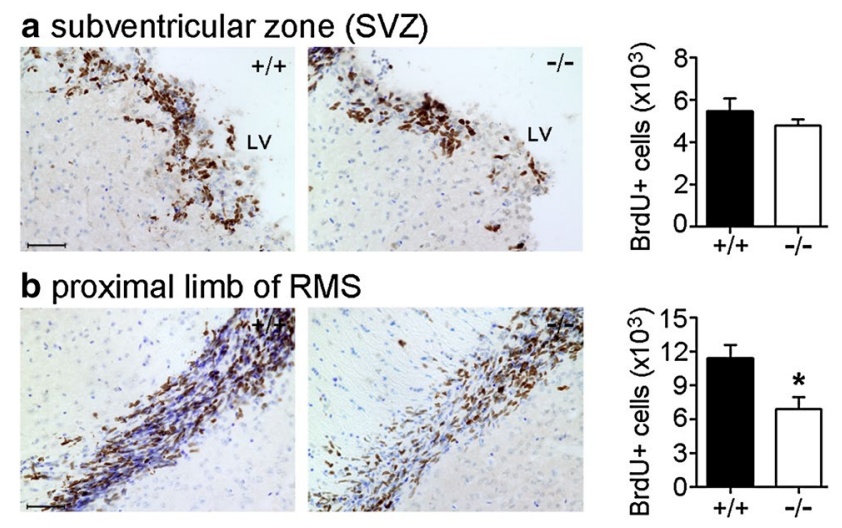

c distal limb of RMS

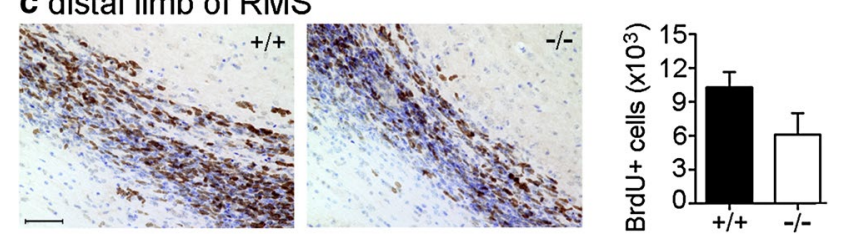

Fig. 1 Bmall deficiency affects NPC proliferation. Representative photomicrographs of BrdU immunoreaction (brown precipitate) and quantification of BrdU-immunopositive cells in the subventricular zone (SVZ) and rostral migratory stream (RMS) in Bmal1 ${ }^{+/+}$mice $(+/+)$ and Bmal1 ${ }^{-/-}$mice (-/-) four days after the first day of BrdU injection. Counterstaining with cresyl violet (blue) was used to highlight the anatomical locations. a Subventricular zone (SVZ), $L V$ lateral ventricle b proximal limb of RMS, $* P<0.05$. c Distal limb of (RMS). $n=4$ mice per genotype. Scale bars $=50 \mu \mathrm{m}$

number of $\mathrm{BrdU}^{+}$cells was significantly different in the proximal RMS between Bmal1 ${ }^{+/+}$mice and $\mathrm{Bmal1}^{-/-}$mice $(P=0.028, n=4$ per genotype) (Fig. 1b). This indicates an effect of Bmall deficiency on progenitor cell proliferation in $\mathrm{Bmal1}^{-/-}$mice.

\section{Bmal1 deficiency affects migration of NPCs to the olfactory bulb}

Four days after the first injection with BrdU, the number of $\mathrm{BrdU}^{+}$cells reaching the olfactory bulb was significantly higher in $\mathrm{Bmal1}^{-/-}$mice as compared to $\mathrm{Bmal1}^{+/+}$mice in both, the granule cell layer $(P=0.028, n=4$ mice per genotype) (Fig. 2a) and the glomerular layer $(P=0.028, n=4$ mice per genotype) (Fig. 2b). In the glomerular layer, the $\mathrm{BrdU}^{+}$cells were present as periglomerular cells, between the glomeruli (Fig. 2b, d). DCX, as a marker for neuronally determined NPCs, was present in the granule cell layer and also periglomerular (Fig. 2d). The percentage of cells co-labeled with BrdU and DCX was significantly higher in Bmal1 ${ }^{-/-}$mice as compared to Bmal1 ${ }^{+/+}$mice in both, the granule cell layer $(P=0.028, n=4$ mice per genotype) (Fig. 2c) and the glomerular layer $(P=0.028, n=4$ mice per genotype) (Fig. 2d) of the olfactory bulb. This indicates 

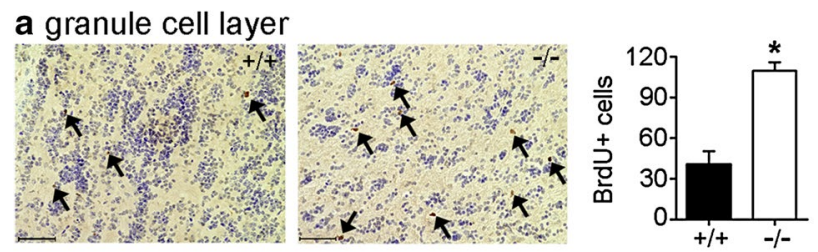

b glomerular layer
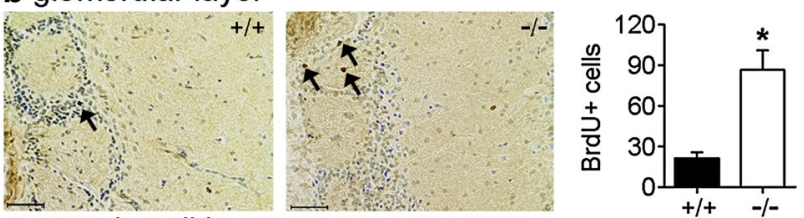

c granule cell layer
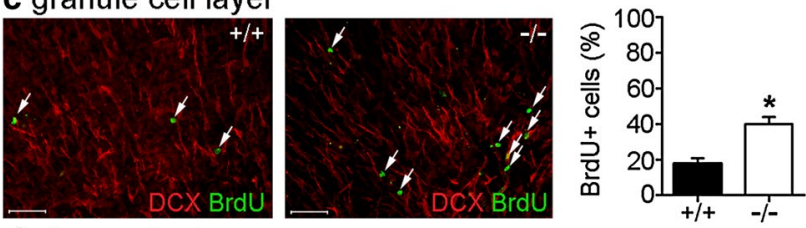

d glomerular layer
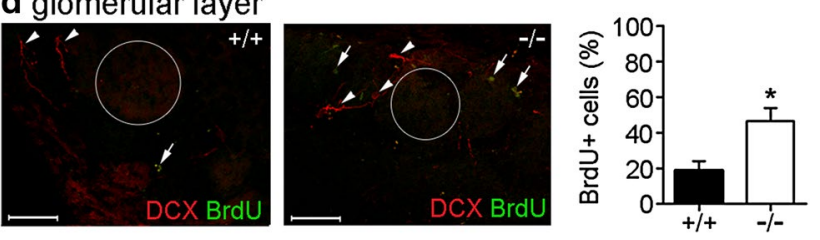

Fig. 2 Bmall deficiency affects the number of newly developed neurons reaching the olfactory bulb within 4 days. Representative photomicrographs and quantification of BrdU-immunopositive cells (arrows) in the olfactory bulb of Bmal1 ${ }^{+/+}$mice $(+/+)$and Bmal1 ${ }^{-/-}$ mice (-/-). BrdU immunoreaction (brown precipitate) and cresyl violet staining (blue) in (a) granule cell layer (b) glomerular layer. Immunofluorescence for BrdU and DCX, as a marker of newly developed neurons, and quantification of $\mathrm{DCX}^{+} / \mathrm{BrdU}^{+}$cell as percentage of total $\mathrm{BrdU}^{+}$cells in (c) granule cell layer, (d) glomerular layer, arrowheads indicate $\mathrm{DCX}^{+}$cells, glomeruli are indicated by circles. $* P<0.05, n=4$ mice per genotype. Scale bars $=50 \mu \mathrm{m}$

that within 4 days more newborn neurons reach the olfactory bulb in $\mathrm{Bmal1}^{-/-}$mice as compared to Bmal1 ${ }^{+/+}$mice.

However, 31 days after the first injection with BrdU, the number of $\mathrm{BrdU}^{+}$cells in the olfactory bulb was not different between Bmal1 ${ }^{+/+}$mice and Bmal1 ${ }^{-/-}$mice (Supplementary Fig. 3). This suggests that in Bmal1 ${ }^{+/+}$mice, newborn neurons migrate faster towards the olfactory bulb.

\section{Bmal1 deficiency affects formation of the glial tube surrounding the RMS and is associated with increased oxidative stress}

The thickness of RMS, determined by the $\mathrm{DCX}^{+}$area, was not different between Bmal1 ${ }^{+/+}$mice and $\mathrm{Bmal1}^{-/-}$mice (Fig. 3a, b). However, the percentage of $\mathrm{GFAP}^{+}$area surrounding the RMS was higher in $\mathrm{Bmal1}^{-/-}$mice as compared to Bmal ${ }^{+/+}$mice $(P=0.028, n=4$ mice per genotype) (Fig. 3a, c). This suggests an enhanced formation of the glial tube surrounding the RMS in Bmal1 $1^{-/-}$mice. This was a RMS
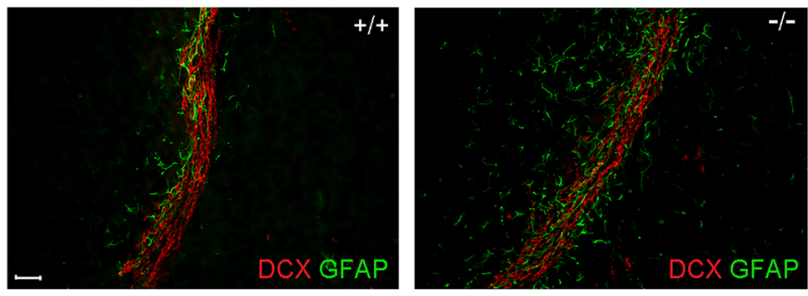

b
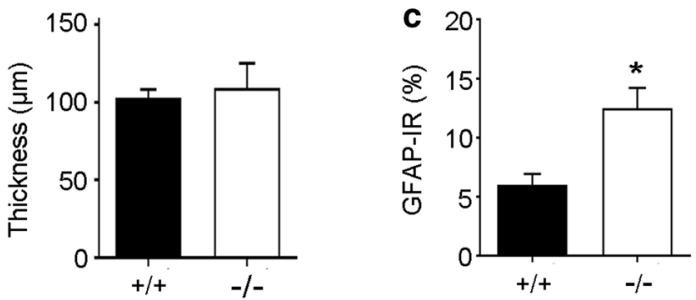

d RMS

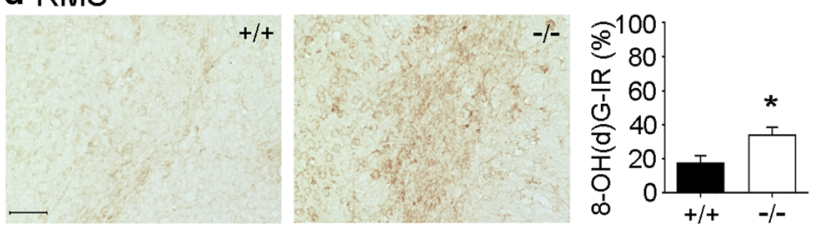

e olfactory bulb
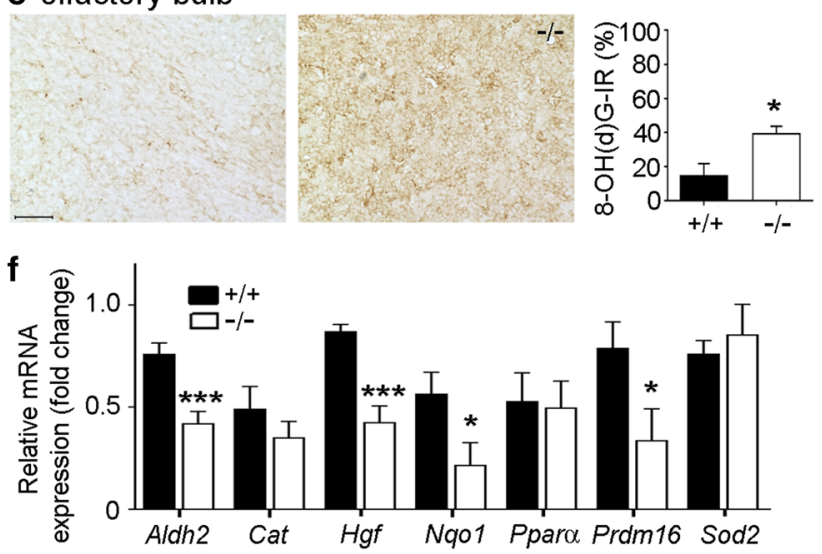

Fig. 3 Bmal1 deficiency affects formation of the glial tube surrounding the RMS, oxidative stress and ROS defense gene expression. a Representative photomicrographs show $\mathrm{DCX}^{+}$migrating neuroblasts forming the RMS surrounded by $\mathrm{GFAP}^{+}$glia cells in $\mathrm{Bmal1}^{+/+}$mice $(+/+)$ and Bmall ${ }^{-/-}$mice $\left(-^{\prime}-\right)$. Scale bar $=50 \mu \mathrm{m}$. b Quantification of RMS thickness, determined by DCX immunoreaction (IR), $n=4$ per genotype c quantification of glial tube surrounding the RMS, determined by GFAP-IR, $* P<0.05, \mathrm{n}=4$ per genotype. d Representative photomicrographs and quantification of $8-\mathrm{OH}(\mathrm{d}) \mathrm{G}-\mathrm{IR}$ in RMS of Bmall ${ }^{+/+}$mice $(n=4)$ and Bmal1 ${ }^{-/-}$mice $(n=5), * P<0.05$. Scale bar $=50 \mu \mathrm{m}$. e Representative photomicrographs and quantification of $8-\mathrm{OH}(\mathrm{d}) \mathrm{G}-\mathrm{IR}$ in the olfactory bulb of Bmal $1^{+/+}$mice $(n=4)$ and Bmal1 $1^{-1-}$ mice $(n=5), * P<0.05$. Scale bar $=50 \mu \mathrm{m}$. f Quantification of relative ROS defense gene expression in Bmal1 ${ }^{+/+}$mice (black bars, $n=9$ ) and Bmal1 ${ }^{-/-}$mice ( $n=7$, white bars), ${ }^{*} P<0.05$, $* * * P<0.001$

associated with a significantly higher cytoplasmic immunoreactivity of the marker for oxidative stress, 8-hydroxy-2'deoxyguanosine $(8-\mathrm{OH}(\mathrm{d}) \mathrm{G})$, in $\mathrm{Bmall}^{-/-}$mice $(n=5)$ as 
compared to Bmal $1^{+/+}$mice $(n=4)$ in the RMS $(P=0.0317$, Fig. 3d) and in the olfactory bulb ( $P=0.0159$, Fig. 3e). Consistently, expression levels of genes involved in detoxification of ROS such as Aldh2 $(P=0.0007), \operatorname{Hgf}(P=0.0002)$, Nqo1 $(P=0.033)$, and $\operatorname{Prdm} 16(P=0.04)$ were down-regulated in the olfactory bulb of Bmal1 ${ }^{-/-}$mice $(n=7)$ as compared to Bmal $1^{+/+}$mice $(n=9)$ (Fig. 3f). These data suggest an increased recruitment of astrocytes to the RMS associated with high oxidative stress in $\mathrm{Bmal} 1^{-/-}$mice.

\section{Bmal1 deficiency affects migration of NPCs, filopodia morphology and phospho-cofilin expression in vitro}

The intrinsic effect of Bmall deficiency on NPC migration was analyzed in neurosphere cultures derived from $\mathrm{Bmal1}^{+/+}$mice (Fig. 4a, supplemental video 1) and Bmal1 ${ }^{-/-}$mice (Fig. 4a, supplemental video 2). $24 \mathrm{~h}$ after seeding, the number of individual cells which migrated out of the neurosphere was higher in Bmal1 ${ }^{+/+}$as compared to Bmal1 $^{-/-}(P=0.0022, n=6$ mice per genotype) (Fig. 4b). Moreover, migration distance was significantly higher in
Fig. 4 Bmal1 deficiency affects migration of NPCs, filopodia morphology and phospho-cofilin expression in vitro. a Representative microphotographs of neurospheres and out-migrating NPCs derived from Bmal1 $1^{+/+}$ mice $(+/+)$ and $\mathrm{Bmall}^{-/-}$mice $(-/-)$. Scale bar $=300 \mu \mathrm{m}$. b Quantification of detached NPCs $24 \mathrm{~h}$ after seeding. The number of detached NPCs was significantly higher in Bmal1 ${ }^{-/}$ as compared to $\mathrm{Bmal1}^{+/+}$, ${ }^{*} P<0.05, n=6$ mice per genotype. c Migration distance and consequently (d) migration velocity were significantly different between Bmal1 $^{+/+}$and $\mathrm{Bmal1}^{-/-}$during the first $24 \mathrm{~h}$ after seeding $* P<0.05, n=4$ mice per genotype. e Representative photomicrographs of neuroblasts $24 \mathrm{~h}$ after seeding with F-actin staining (Phalloidin) and nuclei staining (NucBlue), scale bar $20 \mu \mathrm{m}$. Arrows indicate filopodia. $\mathbf{f}$ Quantification of filopodia number per cell, $* * P<0.01$, $n=6$ mice per genotype $(\mathrm{g})$ Quantification of filopodial length, $* * P<0.01, n=6$ mice per genotype $\mathbf{h}$ representative immunoblots and quantification of phospho (p)-cofilin in NPCs from Bmal1 ${ }^{+/+}$mice and Bmal1 $^{-1-}$ mice. $* P<0.05, n=4$ mice per genotype a
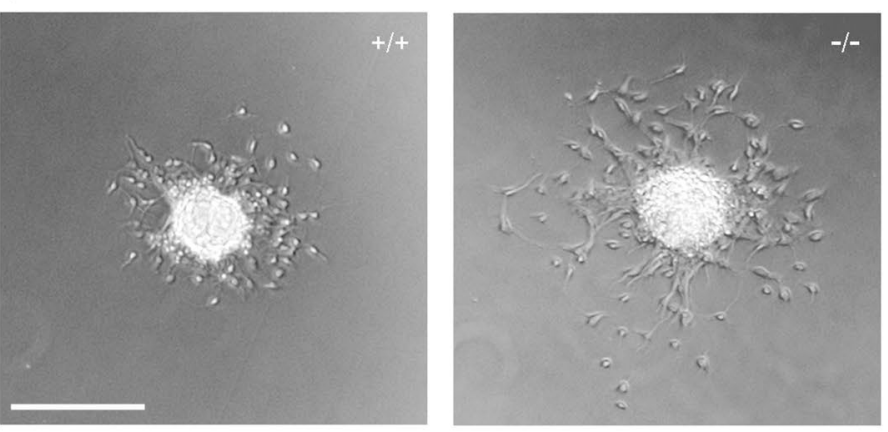

b
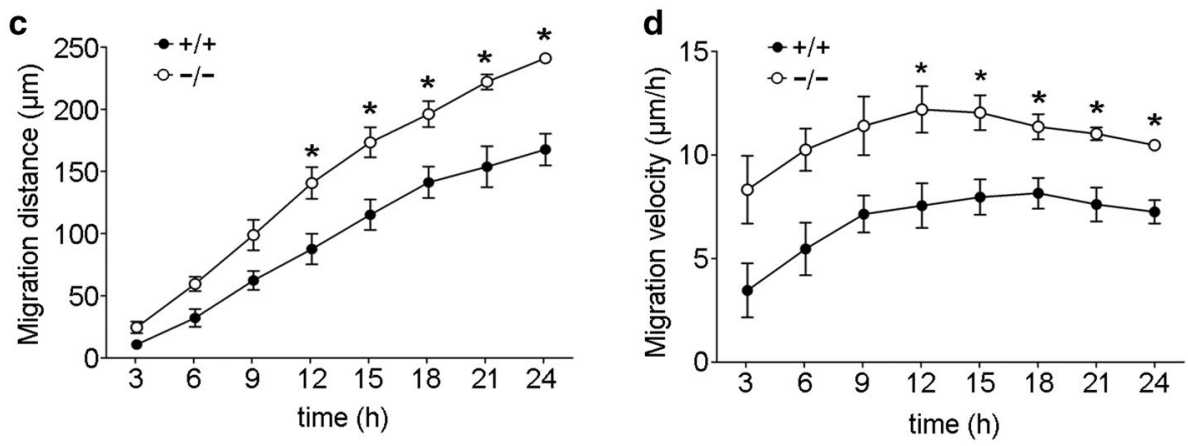

e
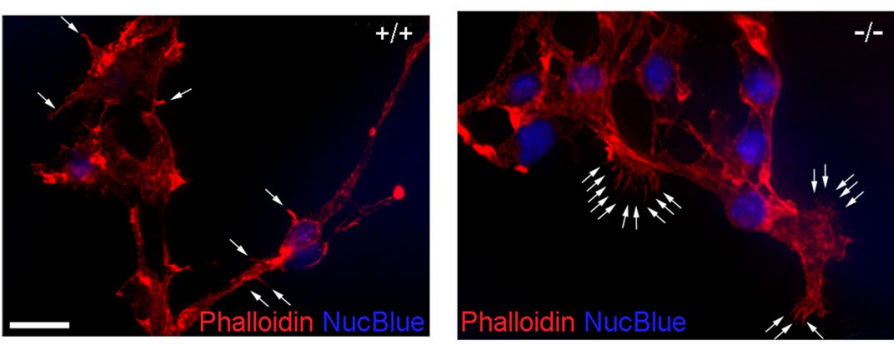

h

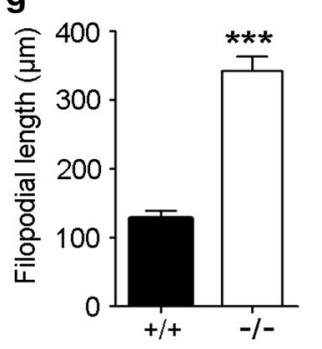

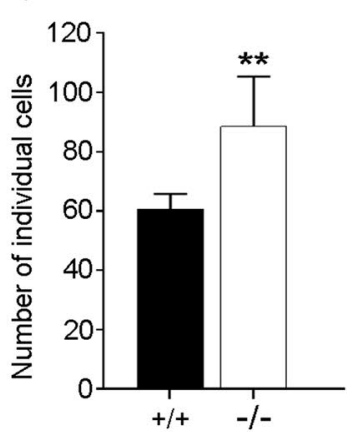

f
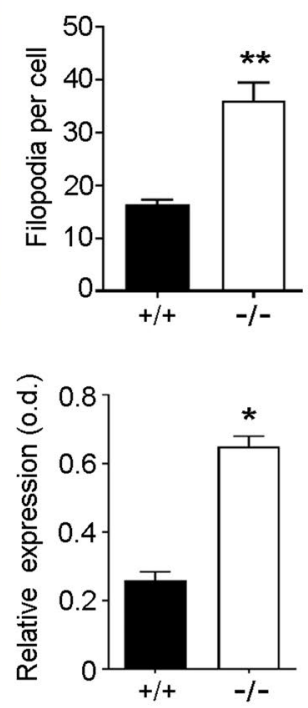
NPCs from Bmal1 $1^{-1-}$ mice as compared to NPCs from Bmal1 $^{+/+}$mice from 12 to $24 \mathrm{~h}$ after seeding $(P=0.0286$; $n=4$ mice per genotype) (Fig. $4 \mathrm{c}$ ). Consequently, migration velocity was also significantly higher in NPCs from Bmal1 ${ }^{-1-}$ mice as compared to NPCs from $\mathrm{Bmal1}^{+/+}$mice from 12 to $24 \mathrm{~h}$ after seeding $(P=0.0286 ; n=4$ mice per genotype) (Fig. 4d). This indicates an intrinsic promoting effect of Bmall deficiency on cell detachment and migration. Morphologically, filopodia were more frequent ( $P=0.0022, n=6$ mice per genotype) (Fig. $4 \mathrm{e}, \mathrm{f})$ and longer $(P=0.0022, n=6$ mice per genotype) (Fig. $4 \mathrm{e}, \mathrm{g})$ in NPCs from Bmal1 ${ }^{-/-}$mice as compared to NPCs from Bmal1 $1^{+/+}$ mice, consistent with enhanced cell motility. Moreover, in NPCs from Bmal1 ${ }^{-/-}$mice the level of phospho-cofilin, the ROS-sensitive mediator of actin dynamics (Bernstein and Bamburg 2010), was significantly higher as compared to NPCs from Bmal1 $1^{+/+}$mice $(P=0.0286, n=4$ mice per genotype) (Fig. 4h), consistent with cytoskeleton stabilization.

\section{Bmal1 deficiency affects ROS production, expression of oxidative stress-related genes and RNA oxidation in NPCs in vitro}

NPCs derived from $\mathrm{Bmal1}^{-/-}$mice showed a significant increase in the number of cells positive for ROS-sensitive Cell ROX® as compared to NPCs derived from Bmal1 ${ }^{+/+}$ mice ( $P=0.0022, n=6$ mice per genotype) (Fig. 5a). Consistently, expression levels of genes involved in ROS detoxification such as $\mathrm{Hgf}, P<0.0001 ; \mathrm{Nqol}, P=0.0039$; Ppar $\alpha, P<0.0001$; and $P r d m, P<0.0001$ were significantly down-regulated in NPCs from Bmal1 ${ }^{-/-}$mice as compared to NPCs from Bmal1 ${ }^{+/+}$mice ( $n=9$ mice per genotype) (Fig. 5b). However, in contrast to the in vivo situation Aldh2 was not down-regulated in NPCs from Bmal1 ${ }^{-/-}$mice. This suggests a cell type-specific expression of ROS detoxification genes. NPCs derived from Bmal1 ${ }^{-1-}$ mice showed significantly higher cytoplasmic $8-\mathrm{OH}(\mathrm{d}) \mathrm{G}-\mathrm{Ir}$ as compared to NPCs derived from Bmal ${ }^{+/+}$mice $(P=0.0079, n=5$ mice per genotype) (Fig. 5c). Cytoplasmic 8-OH(d)G -Ir could not be prevented by pretreatment of NPCs with DNAse but by pretreatment with RNAse (Supplementary Fig. 4), indicating that 8-OH(d)G-Ir represents oxidized RNA. Oxidized RNA was immunopurified from total RNA using an 8-OH(d)G antibody and analyzed by real-time PCR for oxidized 18 s-rRNA as a positive control (Gorg et al. 2008), oxidized mRNAs encoding for $\beta$-actin as our house keeper for real-time PCR and immunoblot which has been shown to be unaffected by oxidation in similar conditions (Shan et al. 2003), or for catalase (Cat) and Sod2 as the genes of interest. In NPCs derived from Bmal1 $1^{-/}$mice, the levels of oxidized $18 s(P=0.0022)$, oxidized $\operatorname{Cat}(P=0.0022)$ and $\operatorname{Sod} 2(P=0.002)$ mRNA were significantly elevated as compared to NPCs derived from Bmall $1^{+/+}$mice $(n=6$ mice per
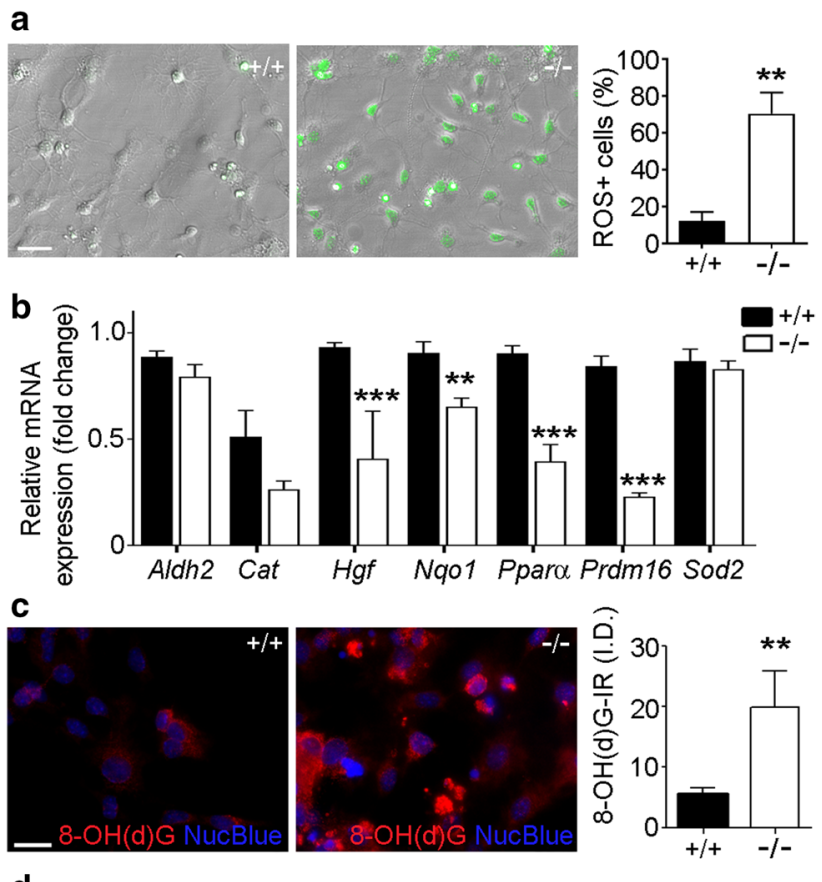

d
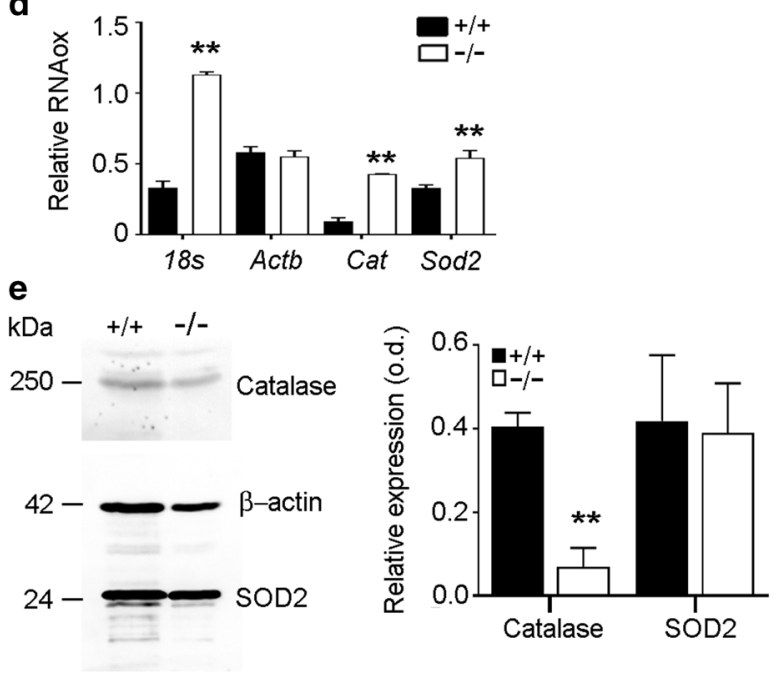

Fig. 5 Bmal1 deficiency is associated with high ROS production, reduced ROS defense gene expression, increased RNA oxidation and decreased catalase levels in NPCs. a Representative photomicrographs and quantification of NPCs derived from $\mathrm{Bmal1}^{+/+}$mice $(+/+)$ and Bmal1 ${ }^{-/-}$mice (-/-) with ROS-sensitive dye CellROX® $24 \mathrm{~h}$ after seeding, $* * P<0.001, n=6$ mice per genotype. Scale bar $=30 \mu \mathrm{m}$ (b) quantification of relative ROS defense gene expression in Bmal1 ${ }^{+/+}$mice and Bmal1 ${ }^{-/-}$mice, $\mathrm{n}=9$ mice per genotype. $* * P<0.01$; *** $P<0.0001$. c Representative photomicrographs and quantification of $8-\mathrm{OH}(\mathrm{d}) \mathrm{G}$ immunoreaction (IR, red) in NPCs as integrated density (I.D.), $* * P<0.01, n=5$ mice per genotype. Scale bar $=20 \mu \mathrm{m}$ d quantification of oxidized RNA (RNAox) levels after immunopurification from total RNA with $8-\mathrm{OH}(\mathrm{d}) \mathrm{G}$ antibody. $* * P<0.001, n=6$ mice per genotype. e Representative immunoblots and quantification of relative catalase and SOD2. $* * P<0.01, n=6$ mice per genotype 
Fig. 6 Treatment with catalase restores wild-type migration phenotype, treatment with hydrogen peroxide mimics Bmall-deficient migration phenotype. a Representative photomicrographs of NPCs from Bmal1 ${ }^{-1-}$ mice (-/-) treated with vehicle (control) or $500 \mathrm{U} /$ $\mathrm{ml}$ catalase (catalase) for $24 \mathrm{~h}$. Scale bar: $200 \mu \mathrm{m}$. b Time course of migration distance and velocity after treatment of NPCs from $\mathrm{Bmal1}^{-/-}$mice with vehicle (control) or $500 \mathrm{U} / \mathrm{ml}$ catalase (catalase) during the first $24 \mathrm{~h}$ after seeding. $* P<0.05, \mathrm{n}=4$ mice per group. c Representative photomicrographs of NPCs from Bmal1 ${ }^{+/+}$mice $(+/+)$ treated with vehicle (control) or $80 \mu \mathrm{M}$ hydrogen peroxide $\left(\mathrm{H}_{2} \mathrm{O}_{2}\right)$ for $24 \mathrm{~h}$. Scale bar: $200 \mu \mathrm{m}$. d Time course of migration distance and velocity after treatment of NPCs from Bmal1 ${ }^{+/+}$mice with vehicle (control) or $80 \mu \mathrm{M} \mathrm{H}_{2} \mathrm{O}_{2}\left(\mathrm{H}_{2} \mathrm{O}_{2}\right)$ during the first $24 \mathrm{~h}$ after seeding. ${ }^{*} P<0.05, n=4$ mice per group. e Quantification of filopodia number in NPCs from Bmal1 ${ }^{+/+}$mice treated with $(+)$or without (-) $\mathrm{H}_{2} \mathrm{O}_{2}$ or in NPCs from Bmal1 $1^{-/-}$mice treated with $(+)$or without $(-)$ catalase. $* P<0.05, n=4$ mice per genotype. $\mathbf{f}$ Quantification of filopodia length in NPCs from Bmal1 ${ }^{+/+}$mice treated with $(+)$or without $(-) \mathrm{H}_{2} \mathrm{O}_{2}$ or in NPCs from Bmal1 ${ }^{-/-}$mice treated with $(+)$or without ( - ) catalase. $* P<0.05, n=4$ mice per group

genotype) (Fig. 5d). As RNA oxidation is associated with insufficient translation into protein (Shan et al. 2003), we analyzed catalase and SOD2 protein levels. In NPCs from $\mathrm{Bmal1}^{-1-}$ mice, catalase protein level was significantly lower as compared to NPCs from Bmal1 $1^{+/+}$mice $(P=0.0087$, $n=6$ mice per genotype) (Fig. 5e). Thus, a higher level of oxidized Cat mRNA is associated with lower catalase protein levels. In contrast, the protein level of SOD2 was not affected by Bmal1 deficiency (Fig. 5e). This suggests a different dynamic in mRNA translation and/or protein stability between catalase and SOD2.

\section{Bmal1 deficiency affects Catalase protein expression and catalase treatment restores wild-type NPC migration phenotype}

Next, we tested whether there is a causal relationship between down-regulated catalase levels and enhanced NPC migration. Treatment of NPCs from Bmal1 ${ }^{-/-}$mice with catalase resulted in a significant decrease in migration distance and velocity from 15 to $24 \mathrm{~h}$ after seeding $(P=0.0286 ; n=4$ mice per group) as compared to vehicle treatment (Fig. 6a, b). This is reminiscent of migration distance and velocity of vehicle-treated NPCs from Bmal1 ${ }^{+/+}$mice (Fig. 6c, d). This indicates a direct causal relationship between catalase and NPC migration. As reduced catalase capacity results in accumulation of hydrogen peroxide $\left(\mathrm{H}_{2} \mathrm{O}_{2}\right)$, we tested whether there is a causal relationship between $\mathrm{H}_{2} \mathrm{O}_{2}$ and NPC migration. Indeed, treatment of NPCs from Bmal1 $1^{+/+}$mice with $80 \mu \mathrm{M} \mathrm{H}_{2} \mathrm{O}_{2}$ resulted in a significant increase in migration distance and velocity $24 \mathrm{~h}$ after seeding $(P=0.0286 ; n=4$ mice per group) as compared to vehicle treatment (Fig. 6c, d). This is reminiscent of migration distance and velocity of vehicle-treated NPCs from Bmal1 ${ }^{-/}$mice and indicates a direct causal relationship between $\mathrm{H}_{2} \mathrm{O}_{2}$ and NPC
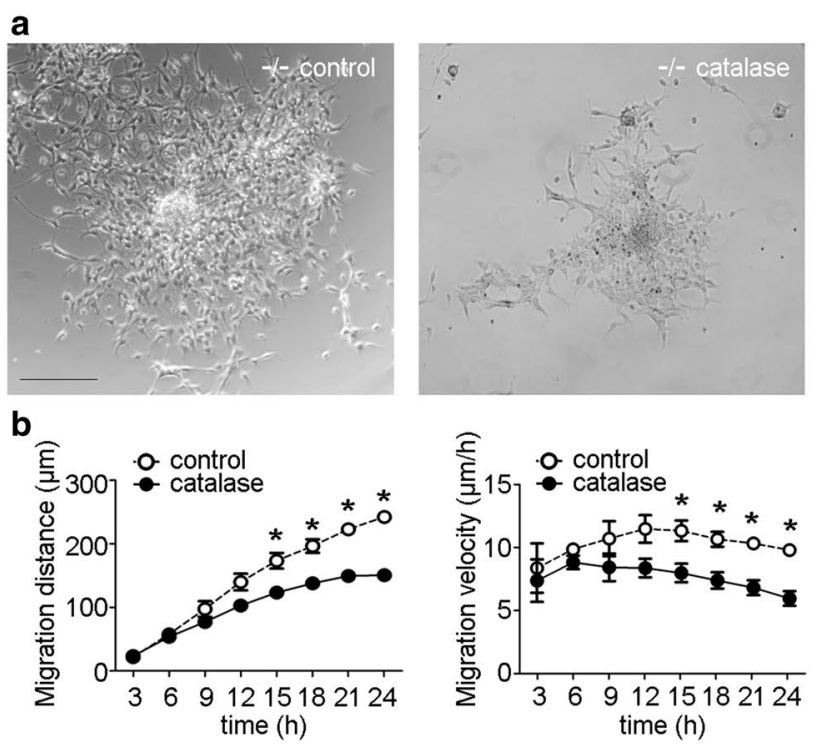

C
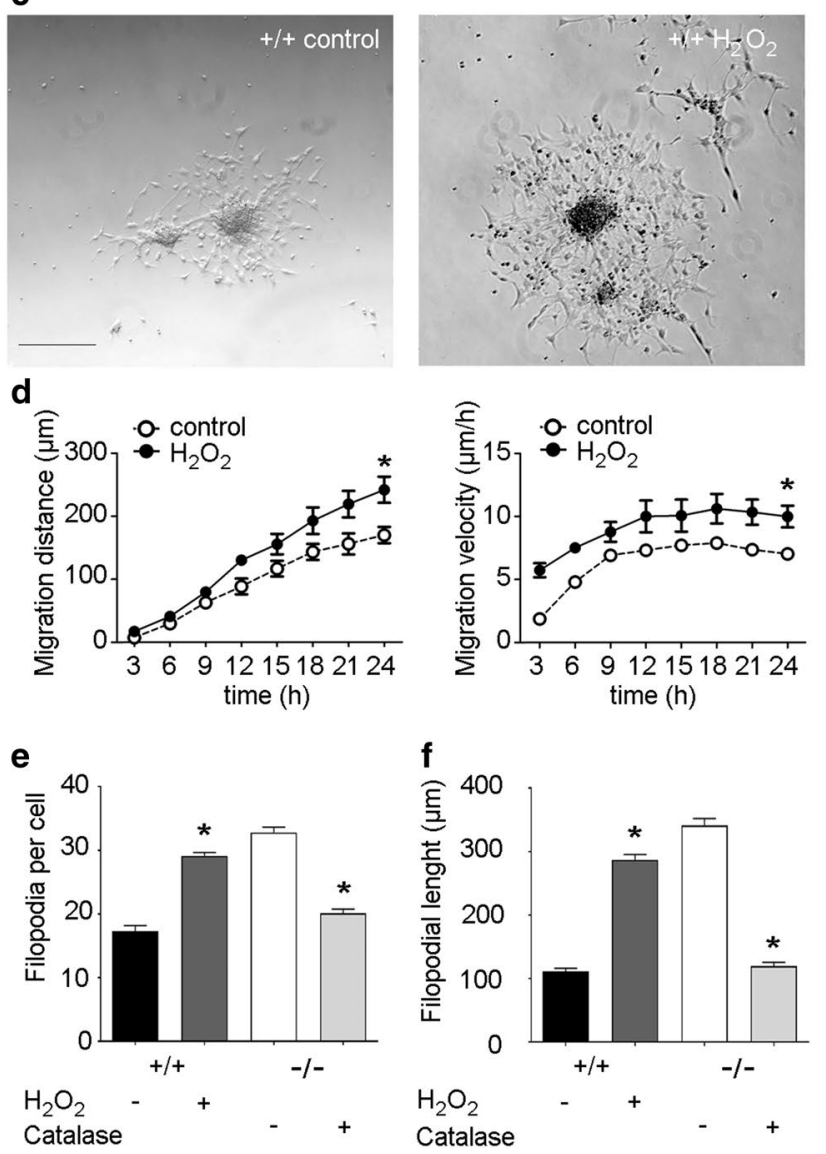

migration. Consistently, the number (Fig. 6e) and length (Fig. 6f) of filopodia was significantly higher in NPCs from Bmal $1^{+/+}$mice treated with hydrogen peroxide as compared to vehicle-treated NPCs from Bmal1 $1^{+/+}$mice $(P=0.0286$, $n=4$ mice per group). Similarly, the number (Fig. 6e) and length (Fig. 6f) of filopodia was significantly lower in NPCs from $\mathrm{Bmal1}^{-/-}$mice treated with catalase as compared to 
vehicle-treated NPCs from Bmal1 ${ }^{-/-}$mice $(P=0.0286, n=4$ mice per group).

In contrast, treatment of NPCs from Bmal1 ${ }^{-/-}$mice with $\mathrm{N}$-acetylcysteine, which serves as a precursor for the antioxidant glutathione, did not affect NPC migration distance and velocity (Supplementary Fig. 5).

\section{Discussion}

The SVZ with RMS represents the most extensive germinal niche and a source for long-range neuronal migration in the adult mammalian brain (Lim and Alvarez-Buylla 2016). Here we show for the first time, that proliferation and migration of NPCs in this neurogenic niche is affected in mice with a targeted deletion of the core clock gene Bmall. Our in vitro studies confirm an increase in migration velocity in NPCs derived from Bmal1 $1^{-1-}$ mice as a consequence of reduced catalase activity and high oxidative stress. Thus, this study provides novel evidence for the role of Bmal1 in regulating NPC migration.

The SVZ (Luskin 1993; Merkle et al. 2004) and RMS (Gritti et al. 2002), give rise to NPCs migrating to the olfactory bulb. Proliferation of NPCs was reduced in $\mathrm{Bmal1}^{-/-}$mice especially in the proximal limb of RMS of the SVZ. This is consistent with our previous observation that Bmall deficiency is associated with reduced proliferation of type $2 b$ NPCs in the SGZ of the hippocampus (Ali et al. 2015). However, despite this reduction in proliferation, we found a significantly higher number of $\mathrm{BrdU}^{+} / \mathrm{DCX}^{+}$, and thus neuronally determined, NPCs in the olfactory bulb of Bmal1 ${ }^{-/-}$mice 4 days after the first BrdU injection. This indicates an accelerated migration of NPCs from Bmal1 $1^{-1-}$ mice to their target region. This is consistent with our previous observation of a higher fraction of newborn cells in the outer two-thirds of the dentate gyrus in Bmal1 ${ }^{-1-}$ mice also indicating enhanced migration (Ali et al. 2015).

In the olfactory bulb, the glomerular layer is the initial site for synaptic processing of odor information. A glomerulus is made up of a globular tangle of axons from the olfactory receptor neurons, and dendrites from the mitral and tufted cells, as well as from cells that surround the glomerulus such as the periglomerular interneurons (Mori et al. 2006). The granular cell layer consists mainly of interneurons that receive input from mitral cells and inhibit their firing by lateral inhibition (Scott et al. 1993). Most of the adult-born neurons, which migrate to the olfactory bulb, target both the glomerular layer and granule cell layer where they mature into interneurons and integrate into the neuronal network (Whitman and Greer 2007). We found a higher number of neuronally determined NPCs in both the glomerular and the granule cell layer. Thus, the effect of Bmal1 deficiency on NPC migration was not exclusive to a subregion of their target in the olfactory bulb.

However, despite an initially higher number of newborn cells in the olfactory bulb of $\mathrm{Bmal1}^{-/-}$mice, the same number of proliferating cells reaches the olfactory bulb in $\mathrm{Bmal1}^{-/-}$mice and Bmal1 ${ }^{+/+}$mice after 31 days. This indicates, that the same number of "slower" Bmal1 ${ }^{+/+}$NPCs and "faster" Bmal1 ${ }^{-/-}$NPCs reach the olfactory bulb eventually. Thus, we do not expect a difference in size or function of the olfactory bulb between the two genotypes. Newly generated neurons in the olfactory bulb are important for odor discrimination (Gheusi et al. 2000; Imayoshi et al. 2008). In Bmal1 $1^{-/-}$mice, the circadian rhythm of odor discrimination is abolished, but the overall odor discrimination sensitivity is not affected (Granados-Fuentes et al. 2011). Thus, Bmall deficiency does not seem to affect integration of adult-born NPCs into neuronal circuits of the olfactory bulb but only migration velocity.

Extrinsic and intrinsic factors modulate migration of NPCs from the SVZ to the olfactory bulb (Murase and Horwitz 2004). The astrocytic tube surrounding the RMS synthesizes and secretes different growth factors which are crucial for migration; such as vascular endothelial growth factor (VEGF) (Bozoyan et al. 2012), and glial cell-derived neurotrophic factor (GDNF) (Paratcha et al. 2006). Furthermore, the interaction of migrating neuroblasts and the surrounding astrocytes via GABA modulates the migration speed (Ma et al. 2005). In Bmal1 ${ }^{-/-}$mice, we found an enhanced formation of glial tube surrounding the migrating neuroblasts. This might facilitate the migration of neuroblasts towards their target regions in the olfactory bulb. The enhanced formation of glial tube may be attributed to generalized astrogliosis reported in the brain of $\mathrm{Bmal1}^{-/-}$mice as a consequence of increased oxidative stress and neurodegeneration (Musiek et al. 2013; Kondratova et al. 2010).

Imbalance of the redox homeostasis in Bmal1-deficient mice has been implicated in accelerated aging, neurodegeneration, cognitive deficits and impaired adult neurogenesis (Musiek et al. 2013; Kondratova et al. 2010; Ali et al. 2015). Cellular oxidative stress reflects an imbalance between the production of reactive oxygen species and the ability to detoxify free radicals that damage all components of the cell, including proteins, lipids, RNA and DNA. Here we show an increase in nucleotide oxidation in the olfactory bulb of Bmal1 $1^{-/}$suggesting a higher risk for DNA and RNA damage. We analyzed a variety of genes involved in cerebral redox homeostasis. NQO1 belongs to the NAD(P) $\mathrm{H}$ dehydrogenase (quinone) family and is important for cellular antioxidant defense. Aldh2 belongs to the aldehyde dehydrogenase family of enzymes that catalyze the chemical transformation from acetaldehyde to acetic acid 
hand functions as a protector against oxidative stress (Ohta et al. 2004). Nqol and Aldh2 are rhythmically expressed with increasing levels during the light phase and dramatically down-regulated in the cerebral cortex of brain-specific Bmal1-deficient mice (Musiek et al. 2013). Consistently, we found a down-regulation of $\mathrm{Nqol}$ and Aldh2 in the olfactory bulb of Bmal1 ${ }^{-/-}$sacrificed during the light phase. Prdm 16 encodes a transcription factor which regulates the cellular redox status and the expression of $\mathrm{Hg} f$ which encodes for an important growth factor in stem cells including NPCs (Chuikov et al. 2010). PPARs (peroxisome-proliferator-activated receptors) are a superfamily of nuclear receptor that regulate the expression of genes associated with lipid metabolism and play an important role for the pathogenesis of neurodegeneration (Heneka and Landreth 2007). Ppara is a target gene of BMAL1 and CLOCK (Oishi et al. 2005) and PAR $\alpha$ agonists upregulate the activity of the enzyme catalase which catalyzes the decomposition of hydrogen peroxide to water and oxygen. Prdm16, Hgf, and Ppara were significantly downregulated in the olfactory bulb of Bmal1 $1^{-/-}$mice. These data emphasize the important role of BMAL1 in the regulation of genes involved in both the production and the detoxification of reactive oxygen species in the brain.

To exclude systemic effects, we further analyzed NPC migration in vitro. Consistent with our in vivo data, NPCs derived from $\mathrm{Bmal1}^{-/-}$mice showed a higher dispersal into individual cells and migrated for longer distance and faster as compared to NPCs derived from Bmal1 ${ }^{+/+}$mice. This indicates an intrinsic, cell autonomous, positive effect of Bmal1 deficiency on NPC detachment and motility. Consistently, NPCs from Bmal1 ${ }^{-/-}$mice showed more and larger filopodia. This is in agreement with the molecular clockwork affecting actin dynamics (Gerber et al. 2013). Moreover, NPCs from Bmal1 ${ }^{-/-}$mice showed a higher level of phospho-cofilin, the ROS-sensitive mediator of actin dynamics (Bernstein and Bamburg 2010). NPCs from Bmal1 ${ }^{-/-}$mice showed increased ROS, equally to increased ROS levels in the brain (Kondratova et al. 2010). Consequently, this was associated with a dysregulation of redox defense genes. Although, in contrast to the in vivo situation, Aldh2 expression was not down-regulated in Bmal1 ${ }^{-/}$-NPCs, suggesting a systemic and/or a cell type-specific effect. However, $\operatorname{Prdm} 16$ encoding for a transcription factor which regulates the redox status and the expression of $H g f$ in stem cells including NPCs (Chuikov et al. 2010) and Ppara which is a target gene of BMAL1 and CLOCK (Oishi et al. 2005) were significantly down-regulated in NPCs from $\mathrm{Bmal}^{-/-}$mice. Importantly, PPAR $\alpha$ agonists upregulate catalase activity (Khoo et al. 2013).
Similarly to the in vivo situation, we found an increase in cytoplasmic 8-OH(d)G-Ir in NPCs from Bmal1-1- mice which could be identified as oxidized RNA. Hence, quantification of gene expression in cells compromised by ROS does not necessarily help to predict protein levels as translation of oxidized RNA is affected (Shan et al. 2003). RNA oxidation in NPCs from Bmal1-1- mice was highly specific similarly as shown for ROS-related neuropathological conditions (Shan et al. 2003; Gorg et al. 2008; Nunomura et al. 1999) where it affects signal transmission, neurotransmission, synaptic plasticity, as well as oscillatory networks in the brain (Haussinger and Sies 2013). Thus, our study suggests RNA oxidation as a potential mechanism for cognitive impairment associated with chronic chronodisruption. Moreover, under neuropathological conditions specifically mRNAs encoding for cytoskeleton relevant genes are oxidized (Shan et al. 2003) indicating a potential role of RNA oxidation in modulating cell migration. Oxidation of Sod2 mRNA was not associated with a decrease in protein levels in Bmal1-deficient mice. However, SOD2 protein has a comparably long half-life (Guruprasad et al. 1990) which is regulated by a deubiquitinating enzyme (Kim et al. 2011). Oxidation of catalase mRNA was associated with decreased respective protein levels consistent with insufficient translation of oxidized mRNA (Shan et al. 2003) and a relatively short half life of the protein (Guruprasad et al. 1990). Decreased catalase activity/level apparently results in accumulation of cellular $\mathrm{H}_{2} \mathrm{O}_{2}$, consistent with a higher susceptibility of Bmal1-deficient primary neurons to $\mathrm{H}_{2} \mathrm{O}_{2}$-induced cell death (Musiek et al. 2013). Treatment of NPCs from Bmal1 $1^{-1-}$ mice with catalase restored the $\mathrm{Bmal1}^{+/+}$migration phenotype, whereas treatment of NPCs from $\mathrm{BMAL}^{+/+}$mice with $\mathrm{H}_{2} \mathrm{O}_{2}$ resulted in accelerated migration velocity (Fig. 7). This indicates a relationship between high ROS levels and NPC migration and is consistent with a general cellular "escaping strategy" from unfavorable oxidative environments (Tsirmoula et al. 2015; Hung et al. 2012; Pani et al. 2010). Moreover, $\mathrm{H}_{2} \mathrm{O}_{2}$ is known to affect F-actin polymerization and cell-matrix adhesion (Mocali et al. 1995). $\mathrm{N}$-acetylcysteine stimulates glutathione synthesis and migration in fibroblast cell line (Tsai et al. 2014) and has been shown to ameliorate symptoms of premature aging in Bmal1 ${ }^{-1-}$ mice (Kondratov et al. 2009). However, treatment of NPCs from Bmal1 ${ }^{-1-}$ mice with $N$-acetylcysteine did not affect migration indicating a disulfide bond-independent effect.

In conclusion, disruption of circadian rhythms not only affects brain, (Kondratova et al. 2010) metabolic (Shi et al. 2013) and cardiac (Schroder et al. 2013) function, but also health in general by inducing a pro-inflammatory state (Lucassen et al. 2016). This study provides a novel 


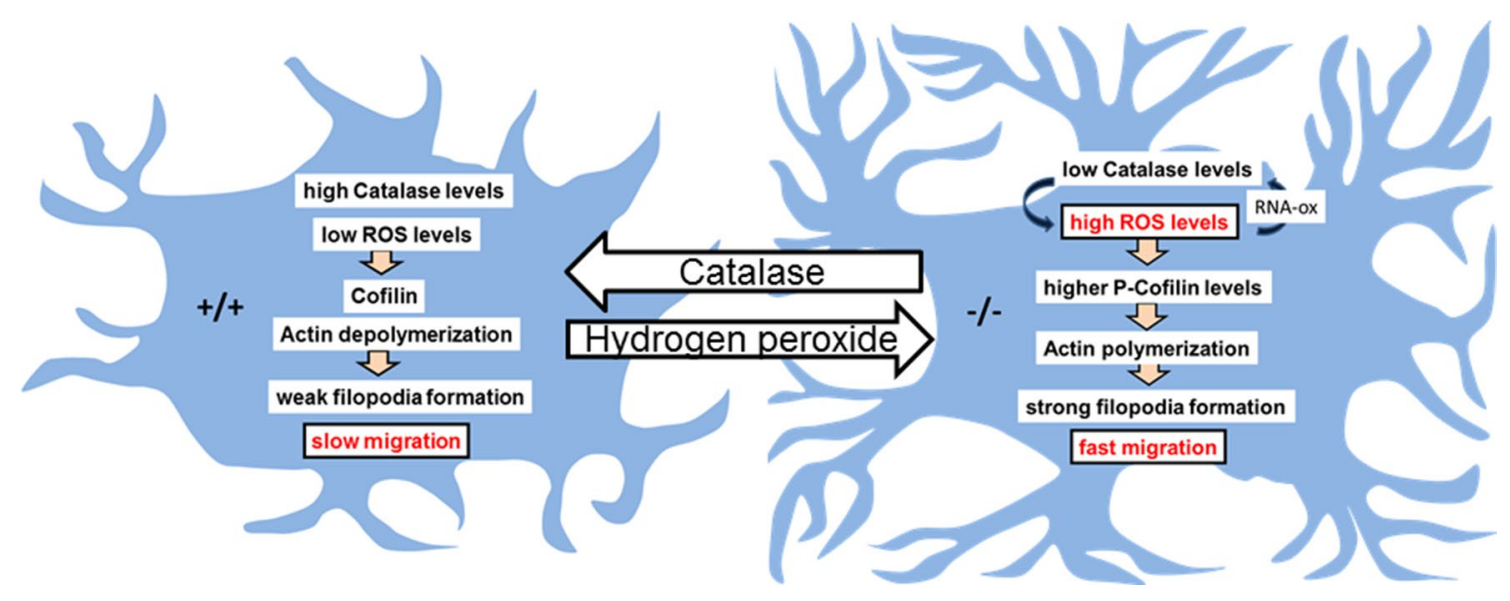

Fig. 7 Model for the effect of Bmall deficiency on neural progenitor cell (NPC) migration. In NPCs of Bmall-deficient mice (-/-) impaired detoxification of reactive oxygen species (ROS) results in enhanced RNA oxidation (RNAox). Oxidation of catalase mRNA leads to decreased catalase protein levels and thus further enhancing ROS accumulation. This is associated with a higher level of the ROSsensitive mediator of actin polymerization $\mathrm{p}$-Cofilin and with stronger

link between a disturbed molecular clockwork, oxidative stress, RNA oxidation and NPC migration. This is of high significance as it might suggest a general effect of chronodisruption on cell migration in health and disease.

Acknowledgements This study was supported by: DFG SFB974 (B.G), DAAD (A. A. H. A.), Stiftung für Altersforschung of the HeinrichHeine-University Düsseldorf, and Forschungskommission of the Medical Faculty of the Heinrich-Heine-University Düsseldorf. We thank U. Lammersen, A. Hallenberger, H. Bellert, and R. Fassbender for excellent technical support. We thank Peter van der Spek, Carsten Berndt, and Helmut Sies for helpful discussions.

Author contributions AAHA and BSH designed and performed experiments, image acquisition, data analysis, designed some figures, and wrote parts of the manuscript. SM established and performed experiments on NPC migration. BS and MV provided essential knowledge for experimental design. BG provided essential knowledge on RNAox immunoprecipitation. MS, KD, and EF provided essential knowledge on neurosphere cultures and analyses. AK performed data mining and pathway analyses. CVG designed and supervised experiments, designed figures, supervised the entire study and wrote the manuscript. All authors reviewed the manuscript and approved its submission.

\section{Compliance with ethical standards}

Conflict of interest The authors declare no competing financial interests.

Open Access This article is distributed under the terms of the Creative Commons Attribution 4.0 International License (http://creativeco mmons.org/licenses/by/4.0/), which permits unrestricted use, distribution, and reproduction in any medium, provided you give appropriate credit to the original author(s) and the source, provide a link to the Creative Commons license, and indicate if changes were made. filopodia formation and higher migration velocity. Exogenous application of catalase in NPCs from Bmal1 ${ }^{-/-}$mice leads to a reduction of ROS levels and to a wild-type $(+/+)$ filopodia and migration phenotype. Vice versa, exogenous application of hydrogen peroxide in NPCs from Bmal1 ${ }^{+/+}$mice leads to a Bmal1 ${ }^{-/-}(-/-)$filopodia and migration phenotype

\section{References}

Ali AA et al (2015) Premature aging of the hippocampal neurogenic niche in adult Bmal1-deficient mice. Aging (Albany NY) 7(6):435-449

Baumann J et al (2014) Comparative human and rat "neurosphere assay" for developmental neurotoxicity testing. Curr Protoc Toxicol 59:12 21 1-24

Baumann JDK, Barenys M, Giersiefer S, Goniwiecha J, Lein PJ, Fritsche E, (2015) Application of the neurosphere assay for DNT hazard assessment: challenges and limitations. In: Kang YJ (ed) Methods in pharmacology and toxicology. Springer, Berlin

Bernstein BW, Bamburg JR (2010) ADF/cofilin: a functional node in cell biology. Trends Cell Biol 20(4):187-195

Bouchard-Cannon P et al (2013) The circadian molecular clock regulates adult hippocampal neurogenesis by controlling the timing of cell-cycle entry and exit. Cell Rep 5(4):961-973

Bozoyan L, Khlghatyan J, Saghatelyan A (2012) Astrocytes control the development of the migration-promoting vasculature scaffold in the postnatal brain via VEGF signaling. J Neurosci 32(5):1687-1704

Bunger MK et al (2000) Mop3 is an essential component of the master circadian pacemaker in mammals. Cell 103(7):1009-1017

Carleton A et al (2003) Becoming a new neuron in the adult olfactory bulb. Nat Neurosci 6(5):507-518

Chazal G et al (2000) Consequences of neural cell adhesion molecule deficiency on cell migration in the rostral migratory stream of the mouse. J Neurosci 20(4):1446-1457

Chuikov $S$ et al (2010) Prdm16 promotes stem cell maintenance in multiple tissues, partly by regulating oxidative stress. Nat Cell Biol 12(10):999-1006

Courtes $\mathrm{S}$ et al (2011) Reelin controls progenitor cell migration in the healthy and pathological adult mouse brain. PLoS One 6(5): 20430

Doetsch F, Alvarez-Buylla A (1996) Network of tangential pathways for neuronal migration in adult mammalian brain. Proc Natl Acad Sci USA 93(25):14895-14900 
Festing MF, Altman DG (2002) Guidelines for the design and statistical analysis of experiments using laboratory animals. ILAR J 43(4):244-258

Fritsche E, Gassmann K, Schreiber T (2011) Neurospheres as a model for developmental neurotoxicity testing. Methods Mol Biol 758:99-114

Gerber A et al (2013) Blood-borne circadian signal stimulates daily oscillations in actin dynamics and SRF activity. Cell 152(3):492-503

Gheusi $\mathrm{G}$ et al (2000) Importance of newly generated neurons in the adult olfactory bulb for odor discrimination. Proc Natl Acad Sci USA 97(4):1823-1828

Goldman SA, Luskin MB (1998) Strategies utilized by migrating neurons of the postnatal vertebrate forebrain. Trends Neurosci 21(3):107-114

Gorg B et al (2008) Ammonia induces RNA oxidation in cultured astrocytes and brain in vivo. Hepatology 48(2):567-579

Granados-Fuentes D et al (2011) Daily rhythms in olfactory discrimination depend on clock genes but not the suprachiasmatic nucleus. J Biol Rhythms 26(6):552-560

Gritti A et al (2002) Multipotent neural stem cells reside into the rostral extension and olfactory bulb of adult rodents. J Neurosci 22(2):437-445

Guruprasad K, Reddy BV, Pandit MW (1990) Correlation between stability of a protein and its dipeptide composition: a novel approach for predicting in vivo stability of a protein from its primary sequence. Protein Eng 4(2):155-161

Hack I et al (2002) Reelin is a detachment signal in tangential chain-migration during postnatal neurogenesis. Nat Neurosci 5(10):939-945

Haussinger D, Sies H (2013) Hepatic encephalopathy: clinical aspects and pathogenetic concept. Arch Biochem Biophys 536(2):97-100

Heneka MT, Landreth GE (2007) PPARs in the brain. Biochim Biophys Acta 1771(8):1031-1045

$\mathrm{Hu} \mathrm{H}$ (2000) Polysialic acid regulates chain formation by migrating olfactory interneuron precursors. J Neurosci Res 61(5):480-492

Hung WY et al (2012) Mitochondrial dysfunction promotes cell migration via reactive oxygen species-enhanced beta5-integrin expression in human gastric cancer SC-M1 cells. Biochim Biophys Acta 1820(7):1102-1110

Imayoshi I et al (2008) Roles of continuous neurogenesis in the structural and functional integrity of the adult forebrain. Nat Neurosci 11(10):1153-1161

Jankovski A, Sotelo C (1996) Subventricular zone-olfactory bulb migratory pathway in the adult mouse: cellular composition and specificity as determined by heterochronic and heterotopic transplantation. J Comp Neurol 371(3):376-396

Kaneko N et al (2010) New neurons clear the path of astrocytic processes for their rapid migration in the adult brain. Neuron 67(2):213-223

Khoo NKH et al (2013) Differential activation of catalase expression and activity by PPAR agonists: Implications for astrocyte protection in anti-glioma therapy. Redox Biol 1(1):70-79

Kilkenny $C$ et al (2012) Improving bioscience research reporting: the ARRIVE guidelines for reporting animal research. Vet Clin Pathol 41(1):27-31

Kim MS et al (2011) Protein stability of mitochondrial superoxide dismutase SOD2 is regulated by USP36. J Cell Biochem 112(2):498-508

Ko CH, Takahashi JS (2006) Molecular components of the mammalian circadian clock. Hum Mol Genet 15(Spec No 2):R271-R277

Kondratov RV et al (2006) Early aging and age-related pathologies in mice deficient in BMAL1, the core componentof the circadian clock. Genes Dev 20(14):1868-1873
Kondratov RV et al (2009) Antioxidant $N$-acetyl-L-cysteine ameliorates symptoms of premature aging associated with the deficiency of the circadian protein BMAL1. Aging (Albany NY) 1(12):979-987

Kondratova AA et al (2010) Circadian clock proteins control adaptation to novel environment and memory formation. Aging (Albany NY) 2(5):285-297

Korf H-W, von Gall C (2012) Circadian physiology. In: Pfaff DW (ed) Neuroscience in the 21st Century. Springer Science + Business Media, Berlin

Lim DA, Alvarez-Buylla A (2016) The adult ventricular-subventricular zone (V-SVZ) and olfactory bulb (OB) neurogenesis. Cold Spring Harb Perspect Biol. https://doi.org/10.1101/cshperspect.a018820

Livneh Y, Adam Y, Mizrahi A (2014) Odor processing by adult-born neurons. Neuron 81(5):1097-1110

Lois C, Alvarez-Buylla A (1994) Long-distance neuronal migration in the adult mammalian brain. Science 264(5162):1145-1148

Lois C, Garcia-Verdugo JM, Alvarez-Buylla A (1996) Chain migration of neuronal precursors. Science 271(5251):978-981

Lucassen EA et al (2016) Environmental 24-hr cycles are essential for health. Curr Biol 26(14):1843-1853

Luskin MB (1993) Restricted proliferation and migration of postnatally generated neurons derived from the forebrain subventricular zone. Neuron 11(1):173-189

Ma DK, Ming GL, Song H (2005) Glial influences on neural stem cell development: cellular niches for adult neurogenesis. Curr Opin Neurobiol 15(5):514-520

Malik A et al (2015) Circadian clock genes are essential for normal adult neurogenesis, differentiation, and fate determination. PLoS One 10(10): e0139655

Merkle FT et al (2004) Radial glia give rise to adult neural stem cells in the subventricular zone. Proc Natl Acad Sci USA 101(50):17528-17532

Mocali A et al (1995) Induction, effects, and quantification of sublethal oxidative stress by hydrogen peroxide on cultured human fibroblasts. Exp Cell Res 216(2):388-395

Mori K et al (2006) Maps of odorant molecular features in the Mammalian olfactory bulb. Physiol Rev 86(2):409-433

Murase S, Horwitz AF (2004) Directions in cell migration along the rostral migratory stream: the pathway for migration in the brain. Curr Top Dev Biol 61:135-152

Musiek ES et al (2013) Circadian clock proteins regulate neuronal redox homeostasis and neurodegeneration. J Clin Invest 123(12):5389-5400

Nunomura A et al (1999) RNA oxidation is a prominent feature of vulnerable neurons in Alzheimer's disease. J Neurosci 19(6):1959-1964

Ohta $\mathrm{S}$ et al (2004) Mitochondrial ALDH2 deficiency as an oxidative stress. Ann N Y Acad Sci 1011:36-44

Oishi K, Shirai H, Ishida N (2005) CLOCK is involved in the circadian transactivation of peroxisome-proliferator-activated receptor alpha (PPAR alpha) in mice. Biochem J 386:575-581

Pani G, Galeotti T, Chiarugi P (2010) Metastasis: cancer cell's escape from oxidative stress. Cancer Metast Rev 29(2):351-378

Panzanelli P et al (2009) Early synapse formation in developing interneurons of the adult olfactory bulb. J Neurosci 29(48):15039-15052

Paratcha G, Ibanez CF, Ledda F (2006) GDNF is a chemoattractant factor for neuronal precursor cells in the rostral migratory stream. Mol Cell Neurosci 31(3):505-514

Perez Estrada C et al (2014) Oxidative stress increases neurogenesis and oligodendrogenesis in adult neural progenitor cells. Stem Cells Dev 23(19):2311-2327

Reppert SM, Weaver DR (2002) Coordination of circadian timing in mammals. Nature 418(6901):935-941 
Schroder EA et al (2013) The cardiomyocyte molecular clock, regulation of Scn5a, and arrhythmia susceptibility. Am J Physiol Cell Physiol 304(10):C954-C965

Scott JW et al (1993) Functional organization of the main olfactory bulb. Microsc Res Tech 24(2):142-156

Shan X, Tashiro H, Lin CL (2003) The identification and characterization of oxidized RNAs in Alzheimer's disease. J Neurosci 23(12):4913-4921

Shi SQ et al (2013) Circadian disruption leads to insulin resistance and obesity. Curr Biol 23(5):372-381

Tsai ML et al (2014) Topical N-acetylcysteine accelerates wound healing in vitro and in vivo via the PKC/Stat3 pathway. Int J Mol Sci 15(5):7563-7578

Tsirmoula $S$ et al (2015) Pleiotrophin-induced endothelial cell migration is regulated by xanthine oxidase-mediated generation of reactive oxygen species. Microvasc Res 98:74-81
Valdameri G et al (2011) Involvement of catalase in the apoptotic mechanism induced by apigenin in HepG2 human hepatoma cells. Chem Biol Interact 193(2):180-189

Vandesompele J et al (2002) Accurate normalization of real-time quantitative RT-PCR data by geometric averaging of multiple internal control genes. Genome Biol 3(7):RESEARCH0034

Whitman MC, Greer CA (2007) Synaptic integration of adult-generated olfactory bulb granule cells: basal axodendritic centrifugal input precedes apical dendrodendritic local circuits. J Neurosci 27(37):9951-9961

Wichterle H, Garcia-Verdugo JM, Alvarez-Buylla A (1997) Direct evidence for homotypic, glia-independent neuronal migration. Neuron 18(5):779-791 